\title{
O FRÁGIL PROJETO HUMANISTA CIVILIZACIONAL REFLETIDO NAS PRISÕES DO BRASIL
}

\author{
Carlos Cariacás ${ }^{1}$
}

\begin{abstract}
RESUMO
Os estabelecimentos prisionais são tidos como ambientes socioeducativos e os planos de educação que regem estes espaços afirmam que nestes se trabalha sob o prisma do humanismo, tendo em vista, um projeto civilizador. Contudo, o relatório da Anistia Internacional (1999) Aqui ninguém dorme sossegado aponta uma série de irregularidades concernentes aos direitos humanos no Brasil. Este relatório coloca a afirmação dos planos de educação na deriva. O presente artigo aborda essas irregularidades à luz do humanismo, conforme delineado por autores em El Correo de la UNESCO (2011). Para a interpretação dos dados usamos da metodologia da Análise do Conteúdo (BARDIN, 2006) que aponta para a fragilidade do projeto civilizador no Brasil que se reflete de maneira mais contundente nos cárceres.
\end{abstract}

Palavras-chave: Humanismo. Civilização. Prisões. Anistia Internacional.

\section{THE FRAGILE CIVILIZATIONAL HUMANIST PROJECT REFLECTED IN PRISONS IN BRAZIL}

\begin{abstract}
Prison establishments are considered as socio-educational environments and the education plans that govern these spaces affirm that in these they work under the prism of humanism, aiming at a civilizing project. However, the report of Amnesty International (1999) Here no one sleeps quietly points out a series of irregularities concerning human rights in Brazil. This report puts the assertion of education plans drifting. The present article addresses these irregularities in the light of humanism, as outlined by authors in The UNESCO Courier (2011). For the interpretation of the data we use the methodology of Content Analysis (BARDIN, 2006) that points to the fragility of the civilizing project in Brazil that is reflected more forcefully in prisons.
\end{abstract}

Keywords: Humanism. Civilization. Prisons. Amnesty International.

\section{INTRODUÇÃO}

No contexto da Pedagogia Social, as prisões se constituem em estabelecimentos para a inclusão e a formação de pessoas privadas de liberdade, ou seja, elas são, ou deveriam

\footnotetext{
${ }^{1}$ Universidade Federal do Amapá. Campus de Santana, Santana - AP. Autor para correspondência:cariacas@unifap.br

Submetido em: $25 / 11 / 2018$

Aceito em: $10 / 12 / 2018$
} 
ser, ambientes educativos. Estes são, ou deveriam ser, pautados por projetos que tenham por escopo o resgate da dignidade humana. De modo que "a proposta educativa da pedagogia social é comprometida com esta mudança social, rompendo com as esperanças sacrificadas a partir de um modelo ético-político que tem por escopo a justiça social e os Direitos Humanos" (GRACIANI, 2014, p. 18). Contudo, é grande a dissonância entre propostas humanizadoras e as práticas de muitos agentes do Estado, que deveriam se incumbir do processo socioeducativo.

O presente texto é um esforço para revelar algumas das facetas da referida dissonância. Para tanto, dividimos o artigo em três momentos distintos: problematização, que exporá a relação entre civilização e humanização enquanto projeto; metodologia, na qual usaremos do método Análise de conteúdo para gerar unidades de compreensão para interpretar o relatório; por fim, a fase da organização e interpretação do texto, na qual, discutiremos o modo como a ausência de uma plataforma humanizadora nas prisões reflete a fragilidade do projeto civilizador do Brasil.

A proposta metodológica se assenta sob a chamada Análise de Conteúdo (BARDIN, 2006) que se estabelece em três fases: pré-análise; exploração do material; tratamento dos resultados, inferência e interpretação.

A pré-análise se deu no momento em que entramos em contato com o relatório e as questões sobre a humanização e a ausência de um projeto civilizacional para as prisões que brotaram da leitura flutuante do texto.

A exploração do material se entende como o processo de codificação do material estudado e a sua relação com outras fontes teóricas a ponto de gerarmos unidades de sentidos. Esta é fase da organização, descrição e relação dos dados identificados.

Por fim, a fase do tratamento dos resultados, inferências e interpretações. Momento de confrontar sentidos e posicionamentos teóricos. Tanto a segunda quanto a terceira fase se constituem, no texto, de maneira entrelaçada. Por fim, como será apresentado o humanismo hoje - segundo os intelectuais que discutem a questão em El Correo de la UNESCO - possui algumas características, a recordar: capacidade de o homem conhecer 
a si; reinvindicação do diálogo; incorporação do eixo ontológico da finitude (o homem é um ser que é vulnerável e sofredor); confrontação do capitalismo racista e a atuação da justiça distributiva. Ao se postular a hipótese de que as bárbaras ações dos agentes de Estado acontecem enquanto reflexo do frágil projeto civilizacional humanista, dialogaremos com as caraterísticas acima de maneira invertida, que dentro da perspectiva da Análise de Conteúdo (BARDIN, 2006) chamamos unidades de compreensão ou de sentido. As unidades que trataremos sinalizam de que forma o modus operandi de agentes impossibilita que: o homem conheça a si; exerça o diálogo; não reflita sobre a sua finitude de maneira saudável; não perceba a lógica do capitalismo racista e, portanto, não tenha acesso a justiça distributiva. Impossibilitando essas práticas, os agentes do Estado negam o reconhecimento da humanidade presente nos prisioneiros.

\section{PROBLEMATIZAÇÃO}

Ouve-se, mas pouco, que o Brasil carece de um projeto civilizacional. Se as mazelas nas periferias e nas ruas dos grandes centros urbanos imprimem, muitas das vezes, a ideia de que a barbárie é o que define o modus vivendi da sociedade brasileira marcada pela pobreza, descaso, abandono das pessoas, o que não se dirá dos estabelecimentos prisionais? O termo "impresso" não caberia para definir a condição de barbaridade que a maioria dos prisioneiros se encontra, mas esculpida seria a palavra correta. Barbaridade esculpida! Assim como o bronze e a pedra recebem de seus modeladores traços quase que indeléveis, assim também, parece ser a vida na prisão.

\footnotetext{
A noção de projeto civilizacional está sendo empregada para definir um conjunto de aprendizado individual e coletivo que possibilita uma vivência voltada, crescentemente, para melhorias sociais e políticas potencializadoras de relações cada vez mais democráticas (REZENDE, 2012, p. 84).
}

Todavia, a ausência de um projeto civilizador é realidade que se amalgama por todo o complexo corpo da sociedade brasileira, mas que se anuncia de maneira mais declarada no sistema penitenciário. Quando se iniciou a colonização, no que seria chamado de América, as potências europeias empregaram, segundo a sua concepção de mundo, um modelo de civilização desenhado pelas ideias humanistas. Este projeto foi imposto pelos estrangeiros, repensado pelos que viviam no Brasil, e por estes adaptados, segundo suas peculiaridades que hoje diríamos culturais; no século XIX, com o Positivismo, a sua força persuasiva se enfraqueceu voltando, todavia, a ser enfatizado em nosso Revista Ifes Ciência, v.4, n.2, 2018 - Instituto Federal do Espírito Santo 
contemporâneo (VELASCO, 2009). Hoje, o humanismo encontra voz em muitos campos de ação social. E a área do sistema prisional é uma das que evoca esta proposta. Quando o assunto é o sistema penitenciário, sobremaneira, isso se observa nas investigações da área jurídica, na qual, o aponta como caminho para a ressocialização, integração e cumprimento da pena. É o que Delmas-Marty (2011, p. 28) chama de humanismo jurídico e que "se está reforzando con la multiplicación de instrumentos jurídicos y de organismos internacionales encargados de supervisar el respeto de los derechos humanos, y también con la aparición de un derecho humanitario y de una justicia penal con miras universales". Comumente o termo humanismo guarda a noção de zelo pelo humano, mirando para o seu bem-estar espiritual e físico, inspira, em suma, o desenvolvimento das potencialidades.

Em se tratando da defesa de uma civilização com marco humanizador o movimento da Anistia Internacional se constitui como um referencial; presente em mais de 150 países o movimento investiga e desenvolve ações para impedir abusos contra os direitos sociais, políticos, civis, culturais e econômicos (ANISTIA, 2018). Em 1999, a Anistia Internacional publicou o relatório Aqui Ninguém dorme sossegado - violações dos direitos humanos contra detentos. Quem finda a leitura de Brasil: nunca mais (ARNS, 2003) - que aborda a tortura no período do regime militar (1964-198) - suspira aliviado pensando que o pior ficou para trás. Livros como Memória de um sobrevivente (2001) e Diário de um detento (2001) nos permite compreender que o fenômeno da tortura resiste. É, ao que parece, um pressuposto cultural.

Observamos em Aqui Ninguém dorme sossegado, que agentes do Estado responsáveis por custodiar a vida das pessoas privadas de liberdade produzem atentados contra a humanização, negando, todavia, o que os documentos de Estado afirmam quanto a função social do Sistema Prisional. As leis brasileiras apostam na reinserção na sociedade da pessoa privada da liberdade, há embutida nelas a esperança da regeneração através do estudo e do trabalho no momento do cumprimento da pena, uma vez que, "o espírito da lei é sempre no sentido de apostar na recuperação da pessoa, mas o grande desafio consiste em criar condições efetivas para que isso ocorra" (SILVA, 2001, p. 27). 
Atualmente, os responsáveis pela educação destacam o teor humanista sobre o qual objetiva o contexto socioeducativo: primando pela "coerência com os processos de humanização e emancipação de homens e mulheres em situação de privação de liberdade (SÃO PAULO, 2015, p. 9)", enfatizando “a educação como instrumento máster de transformação de potencialidades humanas individuais e coletivas (AMAPÁ, 2014, p.17)" e entendendo a "apropriação do saber como um ato civilizatório, como um instrumento de humanização, esse é o princípio que baliza as ações de educação para os privados de liberdade (PARANÁ, 2015,p. 21)". Essa retórica otimista do Estado se choca com o descrito pelo próprio Estado quando o assunto é averiguar as reais condições de vida dos apenados e dos edifícios que abrigam o processo socioeducativo. Segundo o relatório do Ministério Público Federal, "O sistema prisional brasileiro, com suas graves deficiências estruturais, superlotação carcerária e condições desumanas de custódia, tem impingido ao país a nódoa da violação de direitos fundamentais (CNMP, 2016, p. 17). Empregando a palavra dramática para se referir a situação do sistema prisional, o Ministério Público conclamou as instâncias dos poderes para enfrentar com vista a superar os problemas e aponta que é preciso aperfeiçoar a infraestrutura, a legislação e a gestão do sistema prisional.

Conforme Velasco (2009), o humanismo é muito empregado em discursos, porém, muitas das vezes, ele não é especificado, não se sabe de que tipo de humanismo as pessoas se referem. Sabemos que é um fenômeno originado na Antiguidade e que tomou acepções distintas ao longo do tempo (BOKOVA, 2011,p.5). Comumente o localizamos teoricamente como uma produção europeia, a ponto de chegar a se pensar vulgarmente que esta parte do mundo teria direitos de propriedade sobre o assunto. Sem embargo, o humanismo não é refém de grupos étnicos ou espaços geográficos. Ainda no período colonial das Américas, o sentido de humanismo foi redimensionado e adaptado as circunstâncias da cultura e das necessidades locais por força dos pensadores crioulos (VELASCO, 2009). E não ficou restrito aquele período, Karavanta (2011) argumenta que:

La divergencia entre las promesas del humanismo y su función instrumental en el colonialismo, el imperialismo y la trata de esclavos suscitó en el decenio de 1960 una crítica acerba de sus principios ética y políticamente contradictorios. Una consecuencia de esto fue la desconstrucción sistemática del humanismo como categoría universal indiscutible. Esa desconstrucción intensificó la necesidad de reedificar el humanismo con una perspectiva diferente, que tenga en cuenta a los 
que "se ha reconocido como hombres sólo en una época reciente", así como a sus comunidades y culturas respectivas, a menudo diaspóricas, multilingües e interculturales.

Segundo o indiano Sanjay Seth (2011, p. 6), "El humanismo es, entre otras cosas, la afirmación o la intuición de que todos los humanos tenemos en común algo fundamental y un mismo derecho a la dignidad y el respeto". Essa preocupação está disseminada em variadas culturas, a ponto de falarmos em humanismos, conforme vemos no aceno de Liu Ji (2011, p. 25):

Los confucianistas tienen por lema la benevolencia, los moístas el amor universal, los taoístas la compasión y los budistas la bondad afectuosa. Los valores fundamentales de la civilización china pueden considerarse como modelos para el desarrollo de la armonía universal $\mathrm{y}$, por consiguiente, de un nuevo humanismo.

As concepções humanistas produzem suas práxis, isto é, os seus modos de refletir-agirtransformar o humano com o qual as ideias interagem. Sabendo que várias são as correntes humanistas, nos restringiremos a pensar a questão pela ótica de hoje; queremos levantar as práxis humanistas subsistentes atualmente enquanto projeto. $\mathrm{E}$ para oferecer respaldo teórico a esta empreitada usaremos o conteúdo disponibilizado pelo El Correo de la UNESCO (2011). Neste, alguns autores fazem a abordagem da temática sob o título El Humanismo, uma idea nueva. Extraímos desta alguns postulados que serão trabalhados ao largo da pesquisa; oferecemos destaque para os argumentos de Seth (2011); Karavanta (2011); Eze (2011) e Dieterlen (2011).

Segundo Seth (2011), o humanismo possui um construto baseado na: 1) Capacidade de o homem conhecer a si mesmo alicerçado em significados e intenções que dizem respeito a sua vida, 2) reivindicação do diálogo entre as civilizações e diferentes concepções de moralidade.

Por sua vez, Asimina Karavanta (2011) aponta a falência do velho humanismo que serviu aos intentos coloniais e imperialista e que se afiançaram na aposta da racionalidade europeia em detrimento a racionalidade dos colonizados e explorados. Para a autora, o novo humanismo só é possível na medida em que incorpore o eixo ontológico da finitude dada em meio a vulnerabilidade e sofrimento do homem e não da sua racionalidade. 
Michael Onyebuchi Eze (2011) confronta a questão do humanismo hoje com o capitalismo racista que restringe as pessoas da dignidade do trabalho e as segrega a condições de miserabilidade. Deste modo, o humanismo só se pode constituir na medida em que a questão da segregação racial e econômica for enfrentada. Porque aquela é causada por esta. Desse modo, pensamos que o posicionamento de Eze (2011) é completado pelo de Paulette Dieterlen (2011) ao afirmar que o autêntico humanismo só se realiza quando a justiça é distributiva, ou seja, quando o fenômeno da pobreza é encarado com vista a sua superação.

Ora, a leitura do Aqui ninguém dorme sossegado instiga-nos a pensar sobre as ações dos agentes do Estado responsáveis pela custódia das pessoas privadas de liberdade. Denota-se no trajeto dos relatos o teor de desumanidade que esses exercitam deliberadamente e, além do mais, cientes de que não serão punidos. Esta certeza reflete não a falência e muito menos uma crise do sistema ou de um projeto de civilização, mas a debilidade em que este projeto está assentado. Deste modo, esta pesquisa se destina a analisar os elementos que apontam para a fragilidade de um projeto civilizador humanista mediante o modus operandi dos agentes do Estado que estão em contato com os prisioneiros.

Como a UNESCO é um organismo acoplado a Organização das Nações Unidas (ONU), na qual, o Brasil participa como membro e consignatário de tratados sobre Direitos Humanos e prisionais, pensamos que confrontar a vertente humanista discutida por estudiosos colaboradores da organização com os relatos sobre a barbárie nas prisões adquire significado avaliativo e crítico no referente ao questionamento.

\section{IMPOSSIBILIDADES PARA O PROJETO CIVILIZADOR HUMANITÁRIO}

Aqui ninguém dorme sossegado foi organizado em dois momentos: o primeiro, marcado pelas denúncias e, o segundo, apontando experiências que deram certo no processo de garantia da dignidade da vida humana. Nos restringiremos ao primeiro momento tendo em vista o recorte da nossa temática. O relatório está dividido em 8 capítulos nos quais aparecem os seguintes assuntos: mortes sob custódia; tortura e maus-tratos; condições de detenção; um sistema penal em crise; inspeção, apresentação de denúncia e impunidade; mulheres; menores; recomendações da anistia internacional. Ao final é 
disponibilizado um apêndice, no qual, a Anistia Internacional oferece sugestões de como garantir um padrão democrático e justo para a vida dos apenados. O relatório possui 123 páginas e está disponibilizado na internet.

Na sequência partimos para a apresentação dos dados sobre como os agentes impossibilitam a presença de ações humanista fragilizando, desta feita, um possível projeto de civilização e afirmando a negação da condição humana dos apenados.

\section{A negação do conhecimento de si}

Segundo Emile Durkheim (1989), quando o indivíduo vem ao mundo ele já se depara com toda uma estrutura social a qual terá de se adequar; é o que o sociólogo chama de Fato Social, estedefinido como tudo o que é coletivo, exterior ao indivíduo e coercitivo. Partindo desta concepção se pode perceber que o homem será constituído a partir dos modelos sociais empregados, tendo em vista uma dada expectativa da sociedade em relação a ele. Não é à toa que o mesmo Durkheim (1975) afirma em sua Sociologia da Educação que a cada nova pessoa que vem ao mundo o processo de conduzir e educar deverá ser refeito individualmente, isto é, a tarefa de apresentar sentidos de como ser, viver, agir e funcionar na sociedade é, antes de tudo, um empreendimento social. E as instituições manterão essa tarefa ao longo da vida de todos os indivíduos. Quando estes não cumprem com o seu dever e a desordem avança, a anomia (falta de normas, ou incapacidade da estrutura social de prover a determinados indivíduos o necessário para que eles atinjam as metas da sociedade), segundo Durkheim, apodera-se do corpo social e nesse sentido é preciso rever os erros para que a vida tome a sua funcionalidade e finalidade. Deste modo, o sistema prisional é responsável, enquanto instituição social, de educar o homem para que se conheça com vista a evitar a possibilidade da anomia. Ora, logo na introdução do relatório da Anistia (1999, p. 1) nos deparamos com o seguinte relato:

A 10 de dezembro de 1998, enquanto o mundo comemorava o Cinquentenário da Declaração Universal dos Direitos Humanos, 400 presos da cadeia pública de Osasco, em São Paulo, foram arrastados de suas celas por policiais sob o pretexto de uma operação de revista das celas. Em vez disso, os presos foram submetidos a oito horas de violência e humilhação, bem como a um corredor polonês de policiais que lhes desferiam golpes e pontapés, tudo à vista do juiz que autorizara a operação. Durante o espancamento os policiais gritavam "Hoje é Dia dos Direitos Humanos e o direito de preso é esse". 
Partindo da concepção positivista-funcionalista, o caso acima é enquadrado como uma anomia uma vez que, segundo o relatório da Anistia, acontece corriqueiramente no sistema prisional brasileiro. Até o positivismo-funcionalismo, que é uma teoria advinda do meio burguês conservador - marcada pelo esforço por manter a ordem social -, não respaldaria tal tipo de incursão sobre a vida dos apenados. Muito menos tal procedimento se justificaria em outros posicionamentos teóricos. Assim como não se justifica legalmente. Com isso queremos dizer: a tortura não se justifica em qualquer empreendimento racional contemporâneo, assim como não se justifica para o sistema prisional que relata exercitar o humanismo no processo de acompanhamento prisional. Ora, a ação relatada está na contramão da proposta humanista não somente pela tortura, mas devido a sua carga simbólica: dia dos Direitos Humanos e sob a vista do juiz. A tortura envolveu todo o corpo representativo do Estado responsável pela aplicação da pena, do policial ao juiz. O grito dos policiais - "Hoje é Dia dos Direitos Humanos e o direito de preso é esse"- anuncia quem é o preso: o sem direito. Afrontando o Artigo $5^{\circ}$ da Constituição que estabelece que "Todos são iguais perante a lei, sem distinção de qualquer natureza, garantindo-se aos brasileiros e aos estrangeiros residentes no País a inviolabilidade do direito à vida, à liberdade, à igualdade, à segurança (...)" (BRASIL, 2016, p. 13) .Enfim, essa afronta revela mais uma particularidade de quem é o preso para aqueles torturadores agentes do Estado, muito além do não ser cidadão, não é pessoa. Desfiguram-se os traços da humanidade com a aplicação da tortura.

Os gritos dos policiais e o olhar do juiz determinam a metodologia (edu)cativa na qual os presos serão disciplinados, baseada na técnica da redefinição do status social do apenado que será o "sem direito". Passando a ser um ente marcado pela deformidade humana e que não mais se reconhecerá; não somente pelo impacto da ação dos agentes em tentar evadir psiquicamente a sua condição humana, assim como também pelas marcas que a tortura emprega em seus corpos que já não serão seus.

No dia 24 de dezembro de $1997 \ldots$ nós fomos levados todos para o campo de futebol aqui do presídio e obrigados a ficar nus. Depois fomos obrigados a arrastar por uma lama de esgoto sanitário. Neste período de rastejo nós éramos espancados com cacetadas e chutes nas costelas e no final obrigados a beber tal lama. (...). Eles nos tiravam nus das celas e nos colocavam de joelhos no lado de fora do Céu e nos obrigava a nos espancar um ao outro e depois enfiar o dedo um no ânus do outro (ANISTIA, 1999, p.31). 
A tortura é usada como um processo de alienamento do corpo, transformado em objeto disponível aos que detêm o controle. Usando aqui de Foucault (1986, p. 80) que afirma:

(...) o controle da sociedade sobre os indivíduos não se opera simplesmente pela consciência ou pela ideologia, mas começa no corpo, com o corpo. Foi no biológico, no somático, no corporal que antes de tudo investiu a sociedade capitalista. O corpo é uma realidade biopolítica.

Ora, os corpos na sociedade capitalista é um instrumento manejado e controlado de maneira sutil, a mesma sutileza não se passa nas prisões. Sobre o corpo do preso repousa toda a sorte dos males; é manipulado sadicamente por poder dos agentes do Estado sem pudores. Constituindo-se um ato alienador, onde cabe ao agente que detém o poder apresentar as diretrizes para o manuseio corporal.

Nos anexos de Brasil: nunca mais (ARNS, 2003) encontramos um trecho do psicanalista Hélio Pelegrino que apresenta como se dá esse processo de desfiguração humana:

[...] a tortura busca, à custa do sofrimento corporal insuportável, introduzir uma cunha que leve à cisão entre o corpo e a mente. $\mathrm{E}$, mais do que isto: ela procura, a todo preço, semear a discórdia e a guerra entre o corpo e a mente. Através da tortura, o corpo torna-se nosso inimigo e nos persegue. É este o modelo básico no qual se apoia a ação de qualquer torturador. (...) Na tortura, o corpo volta-se contra nós, exigindo que falemos. Da mais íntima espessura de nossa própria carne, se levanta uma voz que nos nega, na medida em que pretende arrancar de nós um discurso do qual temos horror, já que é a negação de nossa liberdade. O problema da alienação alcança, aqui, o seu ponto crucial. A tortura nos impõe a alienação total de nosso próprio corpo, tornando estrangeiro a nós, e nosso inimigo de morte. (...) $\mathrm{O}$ projeto da tortura implica numa negação total - e totalitária - da pessoa, enquanto ser encarnado. $O$ centro da pessoa humana é a liberdade. Esta, por sua vez, é a invenção que o sujeito faz de si mesmo, através da palavra que o exprime. Na tortura, no discurso que o torturador busca extrair o torturado é a negação absoluta e radical de sua condição de sujeito livre. A tortura visa ao avesso da liberdade. Nesta medida, o discurso que ela busca, através da intimidação e da violência, é a palavra aviltada de um sujeito que, nas mãos do torturador, se transforma em objeto.

Pois bem, toda instituição impacta o sujeito a ponto de ele gerar reflexões sobre quem ele é. E o estamento social é de suma importância no processo psíquico de produzir o reconhecimento de si; não é à toa que o pensamento marxista afirma que o lugar do homem no mundo é indicado pelo lugar que ele ocupa no modo de produção. Nesta senda, o apenado se sente provocado pela instituição prisional - lugar que ele ocupa do modo de produção capitalista - a se pensar enquanto ser nela, com ela e a partir dela 
atrelando, destarte, a sua existência a condição de presidiário ou de ex-presidiário (um estigma indelével?). Em O Outono da Idade Média (HUINZINGA, 2010) vemos um caso que prova esse procedimento de simbiose existencial entre o homem e a sua condição de apenado; era costume em aldeias, na festa do santo padroeiro supliciar e matar um prisioneiro como parte das comemorações, registram os relatos da época que haviam condenados que manifestavam a sua aceitação da imolação e não reclamavam da sorte, antes a apontava como justa e necessária pelos seus crimes e pecados cometidos.

Ora, essa conformidade se pereniza no sistema carcerário e se manifesta de variadas maneiras. Não raro, ex-detentos se sentem desconfortáveis ao saírem da prisão e depois, muitos deles, desejam retornar. Como se observa, há um fio que liga o martirizado medieval com o apenado do nosso tempo: a conformidade com o estado de degradação a que foi submetido. E isto se explica pela cultura prisional que fomenta no apenado mudanças em sua identidade manifestadas sob os seguintes aspectos: como na prisão o controle é exercido a ponto de tirar a autonomia do preso, ao sair, ele não saberá tomar decisões; a autoestima é comprometida e, fora da cadeia, ele evidenciará traços de insegurança e sentimentos de incapacidade para lidar com questões simples do cotidiano; como no sistema carcerário as humilhações e patrulhamentos são comuns os apenados passam a se sentir em constante alerta e, uma vez fora, continuará com essa sensação; fora da prisão o ex-presidiário sentirá desconforto e sofrimento no período de transição, visto que tem que se ressignificar axiologicamente confrontando valores antagônicos; voltar ao ambiente familiar não é algo fácil porquê, uma vez que aprendeu a desconfiar de todos na prisão, reproduzirá essa atitude junto aos seus familiares (BARRETO, 2006).

Qualquer experiência duradoura ou intensa deixa marcas indeléveis na vida das pessoas. Por exemplo, a escola é uma experiência que pode ser significativa ou insignificante ao passar dos anos quem a viveu saberá definir. O mesmo se passa com a experiência de presidiário, as marcas ficarão no processo humano de reconhecimento de si. Marcas não se constituem um problema, a questão é: que tipo de marcas são estas e quais as condições do apenado, ao longo da estadia ou ao seu final, de mensurar como lidar com elas - se de maneira civilizacional ou bárbara. A civilizacional parte do princípio de que 
o vivido foi uma experiência que propiciará melhorias no cidadão para que ele exerça as suas potencialidades junto aos seus e a coletividade. A bárbara está assentada no sadomasoquismo que se constitui socialmente como uma enfermidade que se reproduzirá em sucessão, justamente por gerar relação de ódio e prazer enquanto transtornos da alma e que precisa ser compensada e reaplicada em outros de algum modo. Sobre isto, vale lembrar Paulo Freire, quando ele afirma que o sonho do oprimido que não passa por um processo libertador é o de ser opressor. Civilização e barbárie são dois caminhos muito distintos e o sistema prisional aplica ambas as medidas em espaços donde o teor de democracia ou anti-democracia imperam.

Diversamente de outras instituições sociais, o presídio abriga altas taxas de transtornos cognitivos que dificultam a aprendizagem; isto se deve ao fato de que a maioria dos presos provêm de famílias pobres e desestruturadas afetivamente (GOMES, 2012; CASTRO, 2017). Ademais, os índices de transtornos psíquico somáticos é maior do que em qualquer outro tipo de agrupamento humano; mais de $30 \%$ das pessoas apenadas chegaram ao estabelecimento penitenciário com transtornos e outros problemas de ordem psíquica são desenvolvidos durante o confinamento, como a depressão e a ansiedade (GOMES, 2012). A ausência de enfrentamento dessas questões de saúde é sinal do descuido para com a tarefa de mediar a pessoa privada de liberdade em sua busca pelo reconhecimento de si - condição para o estabelecimento do projeto civilizador. Contudo, a omissão e a incursão dos agentes sobre os apenados só acentuam o aparecimento de mais transtornos, dado pela presença da barbaridade desencadeada enquanto violência tanto entre os presos quanto pelos agentes - as linhas do relatório testemunham:

\footnotetext{
A 2 de julho de 1997 um interno da Penitenciária do Roger foi estuprado por seis outros detentos. Consta que a vítima passou a ter pesadelos e sofrer de insônia devido ao medo de voltar a ser atacado (ANISTIA, 1999, p. 26).

No distrito policial de Cariacica, no Espírito Santo [...] o superintendente da polícia prisional de Vitória, em sua visita à carceragem às segundas-feiras, levava presos para submetê-los a tortura e os devolvia mais tarde com total aquiescência do delegado, que então recusava tratamento médico às vítimas. [...] Um dos presos sofria de desmaios diários após ter sido sufocado com um saco plástico (ANISTIA, 1999, p. 36).
}

O espaço socioeducativo da prisão deveria provocar na pessoa privada da liberdade a reflexão sobre o teor do crime praticado e como não mais cometê-lo - esfera do campo moral. Contudo, esse procedimento não é incentivado, muito ao contrário, a prisão provoca no prisioneiro um descentramento de si e o anulamento da revisão moral do 
crime por ele praticado passando, destarte, para o plano da contemplação e ampliação do universo criminal uma vez que em muitos presídios, contrariando tratados internacionais, presos acusados de delitos e condenados ocupam o mesmo espaço. Ademais, a mistura entre categorias de presos distintos provoca, nos mais fracos, a insegurança física.

A 7 de fevereiro de 1999 treze internos perderam a vida durante uma briga entre dois bandos rivais em Pirajuí, uma das novas instituições penais de São Paulo, inaugurada em setembro de 1998. As vítimas, que foram mortas por espancamento e punhaladas, tiveram seus corpos enrolados em colchonetes e queimados. Consta que as autoridades estaduais não haviam separado as várias categorias de presos, acomodando alguns detentos com seus inimigos declarados, sem tomar precauções suficientes para salvaguardar a segurança de todos os internos (ANISTIA, 1999, p. 26).

Em Educação é muito comum falar em interação entre diferentes pessoas com necessidades especiais com os que possuem uma pretensa normalidade. Contudo, em se tratando do sistema prisional, a lógica educativa é outra; não se é possível congregar indivíduos com repertório criminal distintos, uma vez que o procedimento de as não separar ocasiona instabilidades de ordem psíquica e amplia as possibilidades da pessoa avançar na aprendizagem de novas modalidades criminosas. Pois bem, a cultura prisional possui uma moralidade própria, ademais, operacionaliza-se em jogos de poder nos quais, a submissão de pessoas mais vulneráveis é prática corriqueira. Essa manobra entre desiguais, que é mantida e incentivada muitas das vezes pelos agentes do Estado, abriu brechas para o medo e a insegurança, é o que se nota no relato de uma testemunha de um presídio de Manaus:

\begin{abstract}
O senhor diretor, logo que assumiu, começou a dar muitos privilégios aos internos que trabalhavam na cozinha ele também permite esses internos a abrir certas celas para espancar outros internos e isso está gerando revolta entre os outros internos, que vivem trancados e comem mal, pois a alimentação é péssima quando reclamam, eles são espancados, pois os internos são apoiados pelo diretor. [...]. Eles até já esfaquearam outros internos porque o diretor permite que portem armas (ANISTIA, 1999, p. 25).
\end{abstract}

\title{
A negação do diálogo
}

A segunda característica do humanismo é a reivindicação do diálogo e, quanto a esta, a penitenciária não é o lugar por excelência no qual ela se realizará de imediato. Ora, as pessoas que lá se encontram, em um dado momento, romperam com o processo de entendimento com as leis que regem a vida social. O logos social foi agredido. O processo penal testemunha essa ruptura de entendimento entre as partes. Ademais, a 
estadia na prisão é feita contra a vontade do apenado, mas a ação deste contra a lei também foi um ato demandado contra o entendimento social. Diante do crime a "sociedade" reage por meio do sistema jurídico que, por sua vez, impõe as sanções. Aqui não se há diálogo.

O diálogo também não se presenciará de imediato no momento em que o sentenciado entrar no presídio. Neste, o apenado se vê em um mundo hermético no qual o diálogo de pronto se esconde, avultando-se a submissão que a cultura prisional exigirá do condenado mediante o silêncio para que, inicialmente, não se sobreponha àqueles que a mais tempo vivem naquele espaço ou que hierarquicamente possui privilégios. Rupturas é o que rege esse percurso. Por outro lado, a proposta de uma civilização humanizadora carrega o restabelecimento do diálogo como modo de se desfazer das cisões. Contudo, esse caminho não é fácil. A livre expressão é coibida muitas vezes falar no cárcere pode ser um ato perigoso. Não bastando os atritos comuns ao hostil ambiente carcerário, no relatório da Anistia há denúncias de silenciamentos e de manipulação da liberdade de expressão das pessoas presas sob o espectro da tortura.

A Polícia Civil recorre habitualmente à tortura para extrair informação ou confissões. Ainda assim, foram muito poucos os casos arquivados devido a confissões obtidas sob tortura. Alguns presos entrevistados pela Anistia Internacional relataram que, após a tortura, permaneceram incomunicáveis durante vários dias, até que seus ferimentos sarassem. Certos métodos que, segundo consta, são empregados pela polícia brasileira, tais como asfixia, choques elétricos e ameaça de afogamento, deixam poucos sinais externos visíveis. Os procedimentos de queixa ao alcance dos presos e os mecanismos para investigação de denúncias de tortura são extremamente falhos e, consequentemente, há pouca probabilidade de que a defesa disponha de provas dignas de crédito para apresentar ao tribunal em apoio a alegações de confissão obtida (ANISTIA, 1999, p. 33).

Enquanto os delegados da Anistia Internacional conversavam com os detentos, os guardas tentaram intimidar delegados e presos com sua presença constante e dominante. Alguns detentos declararam temer represálias, o que a Anistia Internacional comunicou imediatamente às autoridades (ANISTIA, 1999, p. 36).

Apesar desse movimento de intimidação, silenciamento e controle sobre o que e como se deve falar, os próprios presos se despertam para o diálogo:

\footnotetext{
Nós indignados com a decisão judicial de ter coibido o acesso dos senhores ao interior deste presídio passamos a expor algumas irregularidades que ferem a nossa magna carta. Devido à morosidade da justiça na tramitação dos processos, é gerado um clima de revolta e hostilidade, por parte dos internos, que reflete na conduta dos mesmos. O presídio não é digno de se instalar uma pocilga. Devido às péssimas instalações de caixas de coleta, há uma calamitosa proliferação de doenças infecto-contagiosas que se alastram além dos muros do presídio, atingindo todo o bairro. $\mathrm{O}$ isolado é utilizado indiscriminadamente (ANISTIA, 1999, p. 41)
} 
No instante em que os presos abrem canais de diálogo com a Anistia, se produz uma recusa por parte deles de se submeterem ao silêncio opressor. Reconhecem a fragilidade a que estão inseridos, dos perigos que a vida acarreta. Ademais, conforme testemunhado, o judiciário se prestou - conforme está no relato acima - a fiar a barbárie do silenciamento, esta é a segunda vez no documento em que se demonstra o envolvimento da justiça na permissão de os maus-tratos. Como se observa se tece discursos contra a barbárie feita pelos prisioneiros, e contra a civilização, demandado pelo judiciário no afã de abafar as denúncias de maus-tratos.

\section{A negação do reconhecimento do sofrimento e da finitude humana}

Segundo Asimina Karavanta (2011), o paradigma eurocêntrico apregoa a racionalidade como o elemento comum para os homens pensarem a sua humanidade, contudo, ela discorda deste: o que une os homens é o reconhecimento de sua finitude, do quanto que o sofrimento e a sua vulnerabilidade os oprime. Ora, é justamente esse passo qualitativo no tangente ao reconhecimento do homem enquanto um ente sofredor e finito que falta ser tratado pelos agentes do sistema penitenciário.

Os 17 médicos que trabalhavam no Hospital Central recusaram-se a atender os paraplégicos, alegando que temiam pela própria segurança. Segundo os registros, um paraplégico passou mais de dois anos sem qualquer atendimento médico. A responsabilidade pela assistência aos paraplégicos corria por conta de outros internos, sem qualquer treinamento e sem acesso a medicamentos. O "tratamento" improvisado das escaras que todos apresentavam consistia na aplicação de uma mistura de pó de café e açúcar ao ferimento aberto e no corte e remoção do tecido em decomposição. As escaras se agravaram com o passar do tempo, apresentando decomposição do tecido muscular até ao osso (ANISTIA, 1999, p. 28).

Enquanto os que deviam se responsabilizar pelo zelo se afastam, os companheiros de cela se unem para o cuidado desnudando a falta de sensibilidade humanitária dos agentes de saúde. Ora, a temática do humanismo se faz presente também no campo da medicina, estando circunscrita, segundo Vera-Delgado (2004), na manifestação de respeito relacionada aos aspectos espirituais, psicológicos e sociais do paciente, atentando para as suas inquietudes, interesses e valores. De acordo com o autor, a medicina sofre de ausência humanística uma vez que ela, atualmente, passa por um processo de mercantilização, neste, os profissionais perdem de maneira acelerada o afeto e o respeito pela pessoa. O que antes era uma relação de solidariedade passou a ser encarado como prestação de serviço, no qual quem pode mais é melhor servido. Pois 
bem, o signo do preso é a pobreza, deste modo, o descaso é o que se pode ser ofertado. $\mathrm{Na}$ medida em que os agentes de saúde do Estado optam pelo distanciamento provocam a negação do sofrimento alheio. Negação esta vinda daqueles que se propuseram socialmente a encarar e a fazer o possível para amenizar o padecimento.

O processo de negação do sofrimento se dá com base no estigma social que os presos carregam e que é manifesto tanto fora da prisão quanto dentro dela. O estigma ocasiona o processo do apagamento dessas pessoas aos olhos daqueles que estão em harmonia com a legalidade social. Segundo Goffman (2008) o processo opressor do estigma é a representação da marginalização social a que indivíduos em algum tipo de vulnerabilidade socioeconômica estão inseridos. Essa marginalização demandada na forma de negação faz um acobertamento da identidade da pessoa a ponto dos que estão em contato com ela, mas em patamar socioeconômico distinto, a rechaçarem.

Contudo, se formos pensar "teoricamente", a ideia de médicos ilustrados - dentro da proposta de racionalidade ocidental - tratar pacientes do modo como os médicos do relato em tela trataram os seus é algo inconcebível. Uma vez que a racionalidade aponta de maneira clara as atribuições de cada profissional e o seu dever na sociedade. Esta é uma das crenças da moderna sociologia e que permeia o pensamento de Max Weber, por exemplo. Sem embargo, esta concepção não se realiza no cotidiano das cadeias.

Ainda assentados nas observações de Vera-Delgado (2004) - ao discutir a nefasta intimidade da indústria farmacêutica com a medicina, assim como as atuações mercadológicas que avançam na área da saúde com o propósito de vender intervenções diagnósticas, acrescida pela proliferação de faculdades privadas de medicina, nas quais, a formação de qualidade dos futuros médicos é questionável - advém a percepção de que a fragilidade de um projeto civilizacional humanista impacta de maneira mais saliente aqueles que nada tem a ofertar financeiramente para serem tratados com dignidade. Avultando-se o estigma social, que é só uma faceta da ausência de um projeto mais amplo para pensar a condição humana marcada pela finitude e sofrimento. Em toda essa conjuntura, esvai-se a sensibilidade e se aprofundam as cisões.

\section{Negação da justiça distributiva}


[...] havia 92 homens apinhados em uma única área de detenção com apenas dois banheiros e 16 beliches. Os outros dormiam no pátio sem cobertura contra a chuva [...]. Em uma das celas ocupadas o cano de esgoto que atravessava a cela estava quebrado, espalhando os dejetos das celas superiores. Do lado de fora, ao longo de uma fileira de celas ocupadas, um cano de esgoto aberto, contendo detritos, transbordava provocando um mau cheiro insuportável [...]. Quando ocorre interrupção do fornecimento de água, o que pode durar dias, as condições sanitárias pioram consideravelmente. Muitas das penitenciárias e delegacias visitadas estavam imundas, com lixo e restos de comida espalhados pelo perímetro e as áreas comuns, atraindo ratos e baratas [...]. No Rio de Janeiro alguns detentos reclamaram que a comida entregue por caminhões sem refrigeração muitas vezes chegava estragada devido ao calor. Foi alegado também que os agentes penitenciários obrigam os presos a esperarem durante horas por uma refeição que acaba chegando estragada ou fria (ANISTIA, 1999, p. 43-45).

O sistema carcerário é um modo de marginalizar ao extremo os pobres. A marginalização atenta contra o processo civilizatório porque fomenta a barbárie que será sempre controlada e apresentada pelos donos do poder como a fomentadora dos problemas sociais. A barbárie é estimulada por modelos sociais pautadas em desigualdades socioeconômicas. De sorte que a barbárie é invenção e cria de estimação dos donos do poder, instrumento necessário para manterem o status social no qual se vigem. De modo que, pensar em um processo civilizatório é tarefa delicada e perigosa, isto porque há de se tomar cuidado para não atacar os pobres entregues a barbárie e preservar os donos do poder que produzem sarcasticamente a desordem. Por essa sorte de ideias, a desordem social é bem quista no modelo de desigualdade socioeconômica e a polícia e a estrutura jurídica, muitas vezes, se portam como as executoras legal e moral do arbítrio dos donos do poder - travestido de vontade de toda a sociedade.

No processo civilizatório há de se denunciar e enfrentar o antagonismo dos donos de poder e desvendar as armadilhas da produção da barbárie e ajudar a potencializar as suas vítimas para que se resgatem. Para tanto seria necessário também transformar as ações dos agentes do estado (segurança pública e judiciário) para um novo estatuto existencial pautado no zelo e proteção de todos evitando, desta forma, o múnus de comensais da morte a serviço daqueles que detém o poder. Claro que isso parece utopia, e agora o é, mas países como Bélgica, Dinamarca, Austrália, atingiram este patamar de zelo. $\mathrm{Na}$ articulação do processo civilizatório ter ciência de que aqueles que hoje habitam o cárcere são pobres e que lá estão porque fazem parte de um projeto social excludente e bem articulado é princípio para se começar a discutir a medida de justiça que cabe ser aplicada para os cidadãos. 
Se contemplarmos as gravuras deJean-Baptiste Debret (1768-1848), que retratam as cadeias no Brasil do século XIX, veremos pessoas pretas e pardas (as cores encarnadas da pobreza brasileira), se formos aos relatórios do século XX e XXI sobre o sistema prisional identificaremos a presença maciça de pobres. No documento Mapa do Encarceramento (BRASIL, 2015) foi descrito, entre os anos de 2007 a 2012, em números esta realidade na qual: mais de $60 \%$ da população carcerária é negra; o triplo é composta por jovens em comparação com os não jovens; mais de $40 \%$ tem ensino fundamental incompleto; a metade condenada por crimes contra o patrimônio, $20 \%$ por entorpecentes e oscilando entre 11 a $13 \%$ entre os anos estão os crimes contra a pessoa e outros. Esse é o retrato da periferia e da juventude: sem oportunidades de estudo de qualidade e a margem da profissionalização. O encarceramento é racista e econômico, de modo que, não brancos e pobres são os alvos prediletos.

Michael Onyebuchi Eze (2011) aponta que o capitalismo racista - que segrega os não brancos - é uma afronta ao humanismo uma vez que restringe as pessoas da dignidade do trabalho. Se persistir a falta de acesso a trabalho digno e a justiça social representada pela distribuição de renda e contenção da pobreza - assim como se o Estado continuar tratando esses problemas como sendo de caráter individual e não como uma questão sócio-estatal, a segregação se manterá e o quantitativo de pessoas encarceradas só aumentará. O Levantamento Nacional de Informações Penitenciárias - INFOPEN - de junho de 2014 traz dados preocupantes quanto ao futuro da população carcerária

\footnotetext{
Desde o ano de 2000, essa população cresceu, em média, 7\% ao ano, totalizando um crescimento de $161 \%$ (valor dez vezes maior que o crescimento do total da população brasileira, que apresentou aumento de apenas $16 \%$ no período, média de $1,1 \%$ ao ano). Atualmente, são 607.731 pessoas privadas de liberdade, sendo que 579.423 delas estão em prisões comuns, 27.950 em secretarias de segurança ou carceragens de delegacias e 358 em presídios federais. $\mathrm{O}$ documento registra ainda que se continuarmos nesse ritmo, em 2022 ultrapassaremos a marca de um milhão de indivíduos presos e em 2075, uma em cada dez pessoas estará nessa mesma situação (PARANÁ, 2015, p. 10).
}

Para Paulette Dieterlen (2011), o autêntico humanismo só se realiza quando a justiça é distributiva - postulando a necessidade de se corrigir a distribuição dos bens- e para isto se faz necessário empenho para revisar o uso dos bens.

Conforme se observa no trecho do relatório da Anistia disponibilizado no início deste subitem, quando se diz que agentes carcerários esperam a comida se estragar para Revista Ifes Ciência, v.4, n.2, 2018 - Instituto Federal do Espírito Santo 
depois entregar para os presos, nos damos conta de como este item básico para a sobrevivência passa por um processo de posse temporária indevida pelos agentes com a única finalidade de punir os já legal e existencialmente penalizados. Para combater isso, assinala Dieterlen (2011, p. 18), recordando a concepção kantiana, se faz necessário "aplicar políticas de justicia distributiva que consideren a las personas como seres dignos y capaces de ejercer su autonomía". Ora, leis, discursos e politicas se têm, muitas das vezes. O que não existe é a sua aplicabilidade e vigilância. Neste sentido, denota-se a fragilidade do projeto civilizador.

\section{SOBRE A FRAGILIDADE DO PROJETO CIVILIZACIONAL HUMANISTA}

As instituições sociais tendem a refletir o desempenho macro da sociedade. A cultura da negação da humanidade do presidiário se dá porque na sociedade o projeto civilizacional humanístico ainda está insipiente. Ademais, muito se fala que o sistema prisional está em crise. Ele não está em crise, funciona perfeitamente segundo os intentos de quem o maneja. O que vemos frente ao cenário dessas ideias é que há uma fragilidade nos discursos e nas práticas sociais que não permitem que sintamos e pensemos no estabelecimento de uma civilização humanista.

\section{Como pensar o antagonismo: crise versus fragilidade?}

A ideia de crise é usada vulgarmente para se referir a algo que está fora do controle e que beira ao desastre. Entretanto, a raiz grega remete a noção de cisão e luta, um momento crucial que exige análise e enfrentamento imediato (CARVALHO, 2017). Camila Caldeira Nunes Dias (2017) desmonta a falácia da chamada "crise do sistema carcerário" ao afirmar que o que existe é um projeto para a manutenção do sistema do jeito que está constituído atualmente.

Durante toda a década de 2000 foram muitas as "crises" nas prisões de todo o país. A cada episódio de exacerbação de violência, assistia-se a apresentação de um "plano" de segurança pública ou para o sistema prisional. Qualquer que fosse o plano ou o governo em questão, tais propostas tinham algo em comum: tratavam-se de intervenção do Estado numa perspectiva eminentemente repressiva, que previa a intensificação da atuação das polícias militares - e, algumas vezes, da Força Nacional e das Forças Armadas - e reforçava a importância e a centralidade da prisão através do aprofundamento da política de encarceramento em massa cujos contornos apresentamos antes (DIAS, 2017, p. 24). 
A autora conclui que, de maneira paradoxal, as propostas do Estado para solucionar as crises forjam a criação de mais problemas, agravando os já existentes e reforçam a continuação da "crise prisional". Ademais, o Estado se exime de tratar sobre o evidente, que a conturbação do sistema carcerário é de fundo socioeconômico alicerçado por uma cultura que preza a exclusão e que o governo, por seu turno, incentiva essa situação no momento em que opta por militarizar e enfrentar o problema pela via da repressão e não de políticas públicas.

O aparecimento da crise promove mudanças no cenário das práticas estabelecidas. Crise, de fato, evoca a ideia de que algo novo se postula e precisa ser pensado e de imediato respondido a altura para que o problema não se agrave. Deste modo, o conceito crise remete a possibilidade da mudança (CARVALHO, 2017). Neste sentido, a repressão enquanto modalidade velha e corriqueira no processo de enfrentamento está longe de se figurar como uma crise, antes sim se apresenta travestido de dogma inconteste para os administradores públicos. Onde se há dogma não se permite o levantamento da crise, uma vez que os agentes fundamentalistas do dogma lutam contra a heresia - possibilidade de escolher pensar e fazer as coisas de maneira diferente do defendido pelo núcleo duro de um determinado setor. Em suma, a crise é a manifestação da novidade herética, do rompimento de paradigmas.

Mas se não há crise e sim uma manutenção do sistema, este é promovido somente pelo governo? Há uma cultura de exclusão e marginalização dos mais pobres e que culmina de maneira mais acentuada no sistema prisional. Esta cultura não se restringe aos agentes do Estado, mas permeia a vida do cidadão comum, inclusive do marginalizado e excluído. "Exclusão advinda da sociedade, pois o berço de toda a falha do sistema prisional tem início na educação disseminada pela sociedade (PAULA; MAGALHÃES, 2015, p. 263) ". Ademais, se reconhece que

[...] antes de querer modificar os excluídos, é preciso modificar a sociedade excludente, atingindo, assim, a raiz do mecanismo de exclusão [...] [é] impossível enfrentar o problema da marginalização criminal sem incidir na estrutura da sociedade capitalista, que tem necessidade de desempregados, que tem necessidade, por motivos ideológicos e econômicos, de uma marginalização criminal (BARATTA apud PAULA; MAGALHÃES, 2015, p. 263).

Como se nota, o problema da exclusão faz parte da concepção social brasileira, marcada pelo capitalismo que precisa de uma margem de pessoas desempregadas e ociosas, uma 
vez que a sua estrutura não é projetada para acolher a todos. Desta forma, não se pode negar que o projeto de civilização está assentado em bases que permitem e aceitam a marginalização, feito este que fragiliza se pensar em um projeto amplo e que garanta a dignidade e as potencialidades dos cidadãos, conforme postula o humanismo.

A falha estrutural de se conceber uma sociedade inclusiva, principio para uma civilização humanizada, se salienta por outros aspectos da cultura do desconhecimento estabelecida no cotidiano do país. No ano de 2017, a revista Exame divulgou uma pesquisa do Instituo inglês Ipsos Mori - que viralizou nas redes sociais - sob o título Brasil fica em $2^{\circ}$ em ranking de ignorância sobra a realidade (CALIGARI, 2017). Na sequência aparece o argumento de que o Brasil só perde no ranking para a África do Sul. Esta constatação pode ser averiguada, em suas devidas proporções, em outro ranking inglês elaborado pelo prestigiado periódico financeiro The Economist (2018), este apresenta anualmente o chamado Índice da Democracia - organizado sob as seguintes categorias: Democracia plena, Democracia imperfeita, regimes híbridos e regimes autoritários. Os critérios para avaliar são: processo eleitoral e pluralismo, funcionamento do governo, participação política, cultura política e direitos civis. Hoje, em 2018, o Brasil aparece em 49 , figurando como uma democracia imperfeita. Se visitarmos os resultados de anos anteriores veremos onde o país constantemente perde pontos, que são nos quesitos participação política e cultura política - elementos que denotam o nível de interesse, ou melhor, desinteresse da maioria da população por questões de fundo público ou coletivo. Nestes dois itens o país chega a ficar, inclusive, atrás de países marcados por regimes totalitários. Essa cultura do desconhecimento é o que favorece a manutenção de práticas que estão longe de uma proposta civilizatória humanista. Como em um ambiente de hostilidade encarnada, no qual o brasileiro se posiciona muitas vezes contra os seus direitos e os direitos dos mais vulneráveis, se pode pensar no estabelecimento de uma cultura humanista se, por humanismo, se entende "[...] la afirmación o la intuición de que todos los humanos tenemos en común algo fundamental y un mismo derecho a la dignidad y el respecto?" (SETH, 2011, p. 6).

Pelo exposto, se nota que a ruptura com o sistema excludente e marginalizador não é tarefa para se resolver em curto ou médio prazo. Exigirá tempo e envolvimento de setores que se empenham em fomentar a herética discussão de tratar com humanidade 
aqueles que, em muitos casos são, tanto/quanto qualquer cidadão em liberdade, vítimas do capitalismo racista e da cultura do desconhecimento.

O termo fragilidade é usual no meio médico e está relacionado a: índice severo de mobilidade, endurecimento, vulnerabilidade, declínio de múltiplos fatores (TEIXEIRA, 2008). Aplicando ao tecido da vivência social, diríamos que a fragilidade se traduz enquanto estado de espírito no qual fatores pessoais (baixo teor educacional, capacidade reduzida de metacognição, empatia) e externos (ideologias, instituições colonizadoras da alma - como os meios de comunicação e outros -, a pobreza e a miséria, a riqueza que não se solidariza) agem sobre e no modus vivendi do cidadão a ponto de ele não mensurar com razoabilidade sobre o seu estado no mundo e, muito menos, sobre o status de coerência ou não da realidade na qual está inserido.

A fragilidade repousa na convivência do bem com mal de maneira inconsciente e/ou psicótica. Inconsciente na medida em que o baixo nível de educação aliado a condição de vida adversa a possibilidade de interagir e refletir sobre as circunstancias sócio existenciais anestesia a capacidade metacognitiva do indivíduo. Psicótica na medida em que a noção de bem individual entra em choque com o bem alheio que passa a ser tido como a representação do mal gerando, destarte, a imagem de que o outro - por suas escolhas ou circunstancias de vida - é o inimigo e deve ser penalizado, excluído, negado e apagado do convívio social. Este fenômeno é comum em regimes totalitários e em espaços onde o dogma ou a visão de mundo marcada por etnocentrismo se estabelecem como única possibilidade de vida. "San Agustín afirmava que obligar a alguién a elegir el bien en lugar del mal no era opresión sino caridad" (BYCHOWSKI, 1968, p. 28). Além do mais, "La humanidad puede sentirse legítimamente orgullosa en cualquier época de hombres como Domingo y Francisco, Buenaventura y Tomás de Aquino, como Inocencio III y San Luis, y, sin embargo, ellos no tenían piedad para el hereje" (LEA apud BYCHOWSKI, 1968, p. 28). A dor, o sofrimento e, inclusive, a morte para o outro - este, agora, enquanto representante do mal - são elementos tidos como necessários para o aperfeiçoamento social por parte daquele que se vê como o bem encarnado; não foi à toa que a mentalidade inquisitorial - que não se restringia a instituição eclesiástica, mas que era comum aos contemporâneos - apregoava que a morte na fogueira era um bem para o herege, pois o purificava de seus pecados e 
edificava os corações na concordância com as verdades eternas (GONZAGA, 1993). Por esta sorte, os autos de fé eram tidos como verdadeiras práticas pedagógicas em favor tanto dos que estavam sendo mortos quanto daqueles que piedosamente, ou por gosto sadomasoquista, o assistiam.

Hoje é comum vermos críticas a Inquisição e a outros sistemas que menosprezavam a fagulha de vida dos outros sobre o pretexto de manter a ordem e o bem para todos, mas na prática, esses rituais de extermínio, iniciado pela exclusão e concretizado na tortura, se vivificam em várias instâncias sociais e, de modo relevante, nos ambientes prisionais.

Ora, afirmamos que não se há crise no sistema prisional, assim como também não se há crise na sociedade brasileira, mas o que existe é uma fragilidade civilizacional humanista. Essa afirmativa parte da contradição, na qual, a própria sociedade e o Estado estão inseridos. Se observarmos os discursos do Estado, empregado para tratar o cidadão privado da liberdade, nos damos conta que o humanismo é apregoado como a resolução do problema da inserção deste na sociedade; se visitarmos pesquisas feitas de opinião que atentam para o imaginário das pessoas sobre que país gostariam de ter e de viver notaremos que as afirmativas caminham para um país com justiça, respeito pelo outro, comprometimento (FGV,2017). Como se percebe, são discursos na contramão da prática. É dizer, existe a semente, a ideia do humanismo, porém, não a estrutura. Enquanto sociedade ainda não se gestou uma mentalidade majoritariamente civilizadora, mas se tem ideia dela, assim como se tem concepções humanistas. Prova disto está no relatório da Anistia, quando da presença de projetos no sistema carcerário que deram certo e que mostram o respeito pela humanidade daquele que, em um dado momento de sua vida, viu a sua humanidade se definhar pela via do crime ou pelo impacto das injustiças socioeconômicas.

O Estado de São Paulo adotou em 1996 uma estratégia abrangente para lidar com incidentes prisionais. Essa estratégia dá grande ênfase ao recurso a negociações para resolver tais incidentes. Para crédito das autoridades estaduais, somente uma pessoa morreu desde então, embora os motins, fugas e episódios de tomada de reféns tenham ocorrido em base semanal. A Anistia Internacional vem instando com outros estados para que adotem diretrizes semelhantes (ANISTIA, 1999, p. 30).

\section{CONCLUSÃO}

Observamos, lendo o relatório da Anistia Internacional, Brasil "Aqui ninguém dorme sossegado”, que o humanismo e práticas humanizadoras passam, na maioria das vezes, Revista Ifes Ciência, v.4, n.2, 2018 - Instituto Federal do Espírito Santo 
distantes das portas e dos muros das penitenciárias brasileiras. Contrariando o discurso dos planos de educação do sistema prisional quando afirmam que as bases teóricas para o desenvolvimento das práticas socioeducativas são regidas pelo prisma da humanização ou do Humanismo. Não que não existam práticas humanizadoras, o relatório aponta exemplos bem-sucedidos em prisões brasileiras, nas quais, a humanização é uma realidade.

Com este estudo, nos detivemos aos relatos feitos pelos presos à Anistia nas partes que abordam a incursão dos agentes do Estado sobre a vida dos apenados. As investidas apontam a fragilidade do modelo de civilização na qual a sociedade brasileira está inserida evidenciando, por esta sorte, o reflexo disto nos estabelecimentos prisionais de maneira severa. A fragilidade se manifesta no momento em que os agentes impossibilitam práticas humanitárias produzindo, desta forma, a negação do reconhecimento do preso enquanto pessoa, da abertura para o diálogo, do sofrimento e da finitude humana e, por fim, da justiça distributiva.

Apontar caminhos, muitas vezes, utópicos para solucionar problemas complexos é um dos pontos pelos quais o humanismo é criticado e recusado como uma alternativa pragmática. Contudo, o humanismo carrega consigo o que está entranhado no ser humano: a esperança. Há autores que dizem que a era do humanismo está terminando, como Achile Mbembe (2017) ao refletir que a "crescente bifurcação entre a democracia e o capital é a nova ameaça para a civilização". Porém, há outros que insistem e apostam no contrário. Afinal, não dá para as pessoas dizerem adeus aquilo que não quer que morra.

\section{REFERÊNCIAS}

AMAPÁ (ESTADO). Secretaria Estadual de Educação/Secretaria Estadual de Justiça e Segurança Pública. Plano Estadual de Educação nas Prisões. Macapá: SEE/SEJSP, 2014.

ANISTIA INTERNACIONAL. Atuação. Disponível em: <<https://anistia.org.br/conheca-a-anistia/atuacao/>>Acesso em: 10 set 2018.

ANISTIA INTERNACIONAL. Aqui ninguém dorme sossegado - Violações dos direitos humanos contra detentos. 1999. Disponível em:<<https://www.amnesty.org/download/Documents/140000/amr190091999pt.pdf > Acesso em: 29 jul 2018. 
ARNS, P. E. (coord.) Brasil: Nunca Mais, 33 Ed. Petrópolis: Vozes, 2003.

BYCHOWSKI, G.. Odio y violencia en la sociedade contemporanea. Buenos Aires: Paidos, 1968.

BARDIN, L. Análise de conteúdo. Lisboa: Edições 70. 2006.

BARRETO, M. L.S. Depois das grades: um reflexo da cultura prisional em Indivíduos libertos. Psicologia: ciência e profissão. v.26 n.4 Brasília dez. 2006. disponível em: $<<$ http://pepsic.bvsalud.org/scielo.php?script=sci_arttext\&pid=S141498932006000400006\#*a $\gg>$ Acesso em: 20 set 2018.

Brasil. Constituição da República Federativa do Brasil: texto constitucional promulgado em 5 de outubro de 1988, com as alterações determinadas pelas Emendas Constitucionais de Revisão nos 1 a 6/94, pelas Emendas Constitucionais nos 1/92 a 91/2016 e pelo Decreto Legislativo no 186/2008. Brasília: Senado Federal, Coordenação de Edições Técnicas, 2016.

BRASIL. Presidência da República. Secretaria Geral. Mapa do encarceramento - os jovens do Brasil. Brasília: Presidência da república, 2015.

BOKOVA, I. Editorial. El Correo de la UNESCO. Octubre/Deciembre, 2011, p. 5.Disponivelem:<<http://unesdoc.unesco.org/images/0021/002130/213061s.pdf $>>$ Aces so em: 10 ago 2018.

CALIGARI, L. Brasil fica em 2 em ranking de ignorância sobre a realidade. Exame. 6 dez 2017. Disponível em: https:/exame.abril.com.br/brasil/brasil-fica-em-2o-em-ranking-de-ignorancia-sobre-arealidade/ acesso: 20 set 2018.

CARVALHO, J. S. F.. Os ideais da formação humanista e o sentido da experiência escolar. Educação e Pesquisa. São Paulo, v. 43, n. 4, p. 1023-1034, out./dez., 2017. Disponível em: http://www.scielo.br/scielo.php?pid=S151797022017000401023\&script=sci_abstract\&tlng=pt Acesso em: 29 ago 2018.

CASTRO, B. R.. Relatório de Gestão - supervisão do Departamento de monitoramento e fiscalização do Sistema Carcerário e dos Sistemas de Execução de Medidas Socioeducacionais. Brasilia: CNJ, 2017.

Conselho Nacional do Ministério Público [CNMP]. A visão do Ministério Público sobre o sistema prisional brasileiro - 2016. Brasília : CNMP, 2016.

DELMAS-MARTY, Mireille . Humanizar la Mundialización. El Correo de la UNESCO. Octubre/Deciembre, 2011, pp. 28-31. Disponivel em: http://unesdoc.unesco.org/images/0021/002130/213061s.pdf Acesso em: 10 ago 2018.

DIAS, C. C. N. Encarceramento, seletividade e opressão: a "crise carcerária" como projeto político.Análise. n 28/2017. Brasil: Friedrich Ebert Stftung. 2017. 
DIETERLEN, P. Justicia y dignidad. EI Correo de la UNESCO. Octubre/Diciembre, 2011, pp.16-18. Disponivel em:

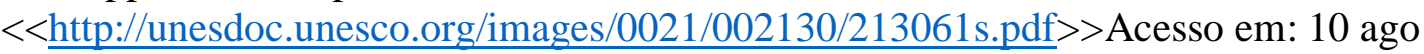
2018 .

DURKHEIM, É. As regras do método sociológico. Lisboa, Editorial Presença. 1989.

DURKHEIM, É. Educação e sociologia. $10^{\mathrm{a}}$ ed. Trad. de Lourenço Filho. São Paulo, Melhoramentos, 1975.

EZE, M. O.Tú eres, luego soy. El Correo de la UNESCO. Octubre/Deciembre, 2011, pp.10-13. Disponivel em:

$<<$ http://unesdoc.unesco.org/images/0021/002130/213061s.pdf $>>$ Acesso em: 10 ago 2018.

FOUCAULT, M. Microfísica do poder (6a ed.). Rio de Janeiro: Graal. 1986.

GOFFMAN, E. Estigma: Notas sobre a manipulação da identidade deteriorada. Rio de Janeiro: LTC, 2008.

FUNDAÇÃO GETÚLIO VARGAS [FGV]. O dilema do Brasileiro: entre a descrença no presente e a esperança no futuro. Rio de Janeiro: FGV. 2017. Disponível em: <<http://dapp.fgv.br/o-dilema-brasileiro-entre-descrenca-no-presente-eesperanca-no-futuro/>>Acesso em: 20 set 2018.

GRACIANI, M. S. S. Pedagogia Social. São Paulo: Cortez, 2014.

GOMES, S.. A pessoa reclusa em contexto prisional: agressividade, sintomas psicopatológicos e apoio social. Dissertação Mestrado em Psicologia. Instituto Universitário Ciências psicológicas, Sociais e da Vida. Lisboa: ISPA, 2012.

GONZAGA, J. B.A Inquisição em seu mundo. 4. ed. São Paulo: Saraiva, 1993.

HUINZINGA, J. O outono da Idade Média. São Paulo: Cosac \& Naify, 2010.

KARAVANTA, A.;Y la hospitalidad? El Correo de la UNESCO.

Octubre/Deciembre, 2011, pp.14-16. Disponivel em:

$<<$ http://unesdoc.unesco.org/images/0021/002130/213061s.pdf $>>$ Acesso em: 10 ago 2018 .

JI, L.Por un mundo armonioso.El Correo de la UNESCO. Octubre/Deciembre, 2011, pp.25-26. Disponivel em:

$<<$ http://unesdoc.unesco.org/images/0021/002130/213061s.pdf >> Acesso em: 10 ago 2018 .

MENDES, L.A. Memórias de um sobrevivente. São Paulo: Companhia da Letras. 2001. 
PARANÁ. Secretaria do Estado da Educação do Paraná/Secretaria do estado da segurança Pública e da Administração Penitenciária. Plano Estadual de Educação no

Sistema Prisonal do Paraná. Curitiba: SEEP/SESPAP, 2015.

PAULA, R. C.; MAGALHÃES, C. A. T. A reinserção do ex-presidiário no mercado de trabalho. Letras Jurídicas. v. 3. n.2. 2o semestre de 2015. Disponível em:

<<http://npa.newtonpaiva.br/letrasjuridicas/wp-content/uploads/2016/09/LJ-0537.pdf >> Acesso em: 14 ago 2018.

SÃO PAULO. Secretaria Estadual de Educação/Secretaria da Administração Penitenciária. Plano Estadual de Educação nas Prisões (2015-2016). São Paulo: SEE/SEAP, 2015.

SETH, S. Adónde va el humanismo? EI Correo de la UNESCO. Octubre/Deciembre, 2011, p. 06-09. Disponivel em:

$<<$ http://unesdoc.unesco.org/images/0021/002130/213061s.pdf $>>$ Acesso em: 10 ago 2018.

REZENDE, M. J.. Ausência de projetos civilizacionais nos primeiros estudos sociais brasileiros. Revista de Ciências Humanas, Florianópolis, Volume 46, Número 1, p. 83-108, Abril de 2012. Disponível em:

$<<$ https://www.researchgate.net/publication/274667553_Ausencia_de_projetos_civiliza cionais_nos_primeiros_estudos_sociais_brasileiros〉> Acesso em: 22 set 2018.

SILVA, R. O que as empresas podem fazer pela reabilitação do preso. São Paulo: Instituto Ethos, 2001.

TEIXEIRA, I. N.. Revisão da literatura sobre conceitos e definições de fragilidade em idosos. Revista Brasileira em Promoçao a Saúde. V. 21. No. 4. p. 297-305. 2008 Disponível em: <<http://periodicos.unifor.br/RBPS/article/view/576〉> Acesso em: 19 set 2018.

THE ECONOMIST. Democracy Indice 2017. Disponível em: $<<$ https://infographics.economist.com/2018/DemocracyIndex/>>Acesso em: 20 set 2018 .

VELASCO, A. Humanismo. México: Universidad nacional Autónoma de México. 2009. Disponível

em: $\langle<$ http://conceptos.sociales.unam.mx/conceptos_final/437trabajo.pdf $〉>$ Acesso 10 ago 2018.

VERA-DELGADO, A. Humanismo y medicina, y algunas reflexiones pertinentes. Revista Colombiana de Cardiología. Vol. 11 No. 6. Noviembre/Diciembre 2004. Disponível em: <<http://www.scielo.org.co/pdf/rcca/v11n6/v11n6a2.pdf 〉>. Acesso em 15 ago 2018. 